\title{
WETENSCHAP
}

\section{Third party litigation funding}

\section{De voordelen, aandachtspunten en aanbevelingen om risico's te beheersen ${ }^{*}$}

\section{A. van der Krans}

\section{Inleiding}

In Engeland en Duitsland is procesfinanciering - third party litigation funding al geruime tijd een bekend fenomeen. ${ }^{1}$ Deze vorm van procesfinanciering is ook in Nederland in opkomst en geeft aanleiding tot tal van juridische en economische $^{2}$ vragen. In dit artikel wil ik een aantal van deze vragen rondom procesfinanciering door derden behandelen. Procesfinanciering door derden definieer ik als de rechtsverhouding waarbij een derde zich tegen een in het vooruitzicht gestelde beloning verplicht om een eiser in een civiele procedure of arbitrage van financiering te voorzien om de kosten van procederen te dekken. Deze derden zijn veelal professionele, (inter)nationaal opererende investeringsmaatschappijen of aan de verzekeringsindustrie gelieerde financieringsmaatschappijen. Deze vorm van procesfinanciering wordt doorgaans aangeduid met de term 'procesfinanciering' of 'third party litigation funding' (afgekort: TPLF). De condities van dit type overeenkomsten verschillen, maar de kern is steeds dat de eiser die meent een vorderingsrecht tot betaling van een geldsom of schadevergoeding te hebben op een wanpresterende wederpartij of laedens, afspreekt om een deel van de uiteindelijke opbrengst van de vordering (na rechterlijke toewijzing of schikking en incasso) af te staan aan een derde die geen bestaande betrokkenheid heeft bij de zaak, te weten de procesfinancier. Deze procesfinancier zal in ruil daarvoor de kosten van advocaten, deskundigen, griffierechten en mogelijk ook de proceskostenveroordeling in geval van verlies van de procedure op zich nemen.

* Dit artikel is een bewerking van mijn bijdrage aan de bundel over collectief verhaalsrecht van het Onderzoekscentrum Onderneming en Recht: A. van der Krans, Third party litigation funding, in: Collectief verhaalsrecht: ondernemingen, belangenorganisaties en hun achterban (Serie Onderneming en Recht, deel 105), Deventer: Wolters Kluwer 2018, H6, p. 99-112.

1 Zie o.a. C. Veljanovski, 'Third party litigation funding in Europe', Journal of Law, Economics and Policy 2012, p. 405 e.v.; M. Tuil \& L. Visscher (red.), New trends in financing civil litigation in Europe - A legal, empirical, and economic analysis, Cheltenham/Northampton: Edward Elgar 2010, p. 1 e.v.; W.H. van Boom, Third-party financing in international investment arbitration, Rotterdam 2011, rapport uitgebracht ten behoeve van de OESO, te vinden op dx.doi.org/ 10.2139/ssrn.2027114.

2 Zie voor een uitgebreide economische analyse van collectieve acties M.G. Faure \& L.T. Visscher, 'Een rechtseconomische visie op collectieve actie', in: Collectieve acties (Preadviezen voor de Nederlandse Vereniging voor Burgerlijk Recht), Zutphen: Uitgeverij Paris 2015, p. 7-64. 
TPLF lijkt op procesfinanciering door middel van 'no cure no pay' (resultaatafhankelijke beloning) en 'contingency fee' (beloning in de vorm van een percentage van de opbrengst van de vordering; ook wel quota pars litis genaamd). Het verschil tussen TPLF en no cure no pay ligt in de partij waarnaar de kosten worden overgeheveld: bij TPLF worden de kosten van de procedure overgeheveld van een eiser naar een derde, terwijl bij no cure no pay de proceskosten worden overgeheveld naar de advocaat. Hoewel het in Nederland aan advocaten in bepaalde gevallen is toegestaan om een resultaatsafhankelijk uurtarief af te spreken met hun cliënt en in sommige gevallen zelfs een vast bedrag of juist een resultaatsafhankelijk percentage van de opbrengst, is de hoofdregel toch dat advocaten hun diensten alleen tegen een uurtarief mogen aanbieden. ${ }^{3}$ De in de Verenigde Staten gangbare wijze van procesfinanciering door de advocaat van de eiser met de contingency fees is in ons land dus in beginsel niet toegestaan.

In deze bijdrage zal ik eerst een verdere uitleg geven over TPLF en de gebruikelijke bedingen in een procesfinancieringsovereenkomst. De juridische kwalificatie van $\mathrm{TPLF}^{4}$ en de link met collectief schadeverhaal ${ }^{5}$ laat ik in deze bijdrage achterwege. Daarna zal ik voordelen, kansen, nadelen en risico's bespreken, om af te sluiten met reguleringsmogelijkheden en aanbevelingen.

\section{TPLF en de procesfinancieringsovereenkomst}

De procesfinancieringsovereenkomst regelt de verhouding tussen de procesfinancier en de eiser. Daarbij spelen allereerst financiële afspraken een rol, zoals de (potentiële) vergoeding voor de procesfinancier en de kosten die hij in ruil daarvoor dient te dragen, maar ook afspraken over de verdeling van bevoegdheden, zoals het recht om de advocaat te kiezen die de procedure zal voeren, of en zo ja welke, rechtsmiddelen worden aangewend, en wanneer en onder welke voorwaarden er geschikt zou kunnen worden. Het Nederlandse recht kent nauwelijks regelgeving die rechtstreeks betrekking heeft op de rechtsverhoudingen tussen de procesfinancier, de gefinancierde eiser en zijn advocaat. Partijen zijn in beginsel vrij om af te spreken wat zij willen. Er zijn in de procesfinancieringsovereenkomst dan ook vele variaties mogelijk.

3 Verordening op de praktijkuitoefening (onderdeel Resultaatgerelateerde Beloning) van de Nederlandse Orde van Advocaten, laatstelijk gewijzigd door Besluit van het College van Afgevaardigden van de Nederlandse Orde van Advocaten van 25 juli 2013, Stcrt. 2013, 20779.

4 De juridische kwalificatie van TPLF laat ik achterwege. Ten eerste is dit uitstekend geanalyseerd door Luiten. Ten tweede is het niet zo spannend. Luiten vergelijkt TPLF met een koopovereenkomst, geldleningsovereenkomst, verzekeringsovereenkomst en samenwerkingsovereenkomst, en komt uiteindelijk tot de conclusie dat TPLF weliswaar een aantal kenmerken heeft van de genoemde bijzondere overeenkomsten, maar geen van alle daadwerkelijk is. Hij komt tot de conclusie dat de procesfinanciersovereenkomst een overeenkomst sui generis is. J.L. Luiten, Third party litigation funding, een korte introductie, Den Haag: Boom juridisch 2017, p. 32.

5 Zie over collectief schadeverhaal het uitstekende themanummer van Ondernemingsrecht 2017, afl. 10/11 met o.a. M.H.C. Sinninghe Damsté \& T.M.C. Arons, 'Collectief schadeverhaal bij kartels in de financiële sector; zegen of vloek’, p. 464-472 en J. de Bie Leuveling Tjeenk \& J.B. van de Velden, 'Collectief schadeverhaal vanuit de optiek van de aangesproken partij', p. 473-484. 
Qua verplichtingen van de financier is de essentie van een procesfinancieringsovereenkomst uiteraard dat de financier de kosten van het proces draagt. Voorts zal veelal overeen worden gekomen dat de financier tevens het risico draagt van een proceskostenveroordeling. Wanneer de vordering kan worden verhaald, is gebruikelijk om eerst uit de opbrengst de kosten aan de financier te vergoeden en dan over het restant de verdeling aan de hand van het afgesproken percentage te berekenen. De financier krijgt dus bij succes zijn kosten vergoed en zijn winstmarge. Toch zijn de kosten ook bij het verhalen van een positief resultaat van belang. Hoewel de kosten worden vergoed, leveren ze voor de financier geen nettowinst op. Elke euro die is uitgegeven om een vordering te verhalen, is er een waarover achteraf niet de winstmarge wordt verkregen. Kosten blijven derhalve relevant, ook bij succesvolle schadeafwikkeling.

Qua verplichtingen van de eiser zijn eveneens vele variaties denkbaar. Mogelijk zal de inhoud van de procesfinancieringsovereenkomst geheim moeten worden gehouden. Daarnaast geldt dat de gefinancierde eiser moet meewerken aan het verhalen van de vordering. De belangrijkste verplichting is die tot het afdragen van een aandeel in de opbrengst van de vordering. ${ }^{6}$ De percentages die door procesfinanciers worden bedongen, lijken zich veelal te bevinden tussen de 20 en $40 \% .{ }^{7}$ Mogelijk zal de komende jaren de concurrentie tussen procesfinanciers toenemen, wat een verlaging van de bedongen percentages tot gevolg kan hebben. Dit marktwerkingseffect was ook in andere jurisdicties waarneembaar. ${ }^{8}$ Op het reguliere quota pars litis-beloningsmodel zijn verschillende varianten denkbaar. Om de procesfinancier een additionele prikkel te geven om een zo hoog mogelijk resultaat te bereiken, kan een progressieve beloningsschaal overeen worden gekomen. Het omgekeerde is ook denkbaar, door een degressieve beloningsschaal af te spreken, om zo onredelijk hoge beloningen voor de procesfinancier te voorkomen. Beide modellen kunnen worden aangevuld door een beloningstrap, gebaseerd op het verloop van de procedure. Een voorbeeld hiervan is dat de procesfinancier een lager percentage verkrijgt wanneer de zaak geschikt wordt voordat een gerechtelijke procedure is geëntameerd en een hoger percentage bij een gunstig vonnis. Voor hoger beroep zal dan een nog hoger percentage gelden. Wordt een progressieve/degressieve beloningsschaal gecombineerd met een beloningstrap, dan wordt dit in een matrix van percentages weergegeven.

6 Als alternatief wordt de vordering gecedeerd aan de procesfinancier, die zich ertoe zal verplichten om van de op de vordering te realiseren opbrengst een percentage te betalen aan de cedent. In dit model zijn per definitie nauwe banden aanwezig tussen financier en advocaat. De cliënt is immers het claim vehicle, veelal vertegenwoordigd door de financier. De cliënt is niet de cedent/ eiser. Wel kan worden aangenomen dat de advocaat in een dergelijk model ook te waken heeft over de belangen van de eisers.

$7 \quad$ Zie R. Philips, Litigation funding in faillissement, TvI 2016, afl. 11, p. 75-85 en S. Liesker, geciteerd in Advocatenblad 2014, afl. 5, p39.

8 M. de Morpurgo, A comparative legal and economic approach to third-party litigation funding, Cardozo Journal of International and Comparative Law (19) 2011, p. 343-412. 


\section{De voordelen of kansen van TPLF}

In het onderstaande zal ik de voordelen en kansen die TPLF biedt, bespreken en kwalificeren.

\subsection{Access to justice}

Partijen die het ontbreekt aan de middelen om een procedure te voeren, kunnen dit met behulp van een procesfinancier toch doen. Bij onvoldoende vermogende partijen dient niet alleen te worden gedacht aan particulieren, al dan niet in de hoedanigheid van consument of werknemer, maar ook aan kleine ondernemers. De beschikbaarheid van gesubsidieerde rechtsbijstand is de afgelopen jaren beperkt en de eigen bijdragen zijn verhoogd. TPLF kan de toegang tot het recht voor onvoldoende vermogende partijen vergroten. Dit potentiële voordeel van TPLF wordt inherent ingeperkt door het commerciële oogmerk van procesfinanciers. Procesfinanciers stellen immers hoge eisen aan de omvang en haalbaarheid van de vordering alsmede de verhaalsmogelijkheden bij de wederpartij. De particulier met een kleine, individuele schadeclaim is derhalve meestal niet aantrekkelijk voor een financier.

\subsection{Bargaining power}

TPLF stelt minder vermogende partijen niet alleen in staat om een zaak aan de rechter voor te leggen, maar zorgt er tevens voor dat deze partijen eenmaal daar ook op gelijkere voet staan met sterkere, meer vermogende partijen. De buidel van de gefinancierde is met de procesfinancier achter zich een stuk dieper. Daardoor kunnen trainerende tactieken van de wederpartij minder effectief zijn en kan meer pariteit worden bereikt in bijvoorbeeld de mogelijkheden tot het inhuren van een expert en het doen van onderzoek. De aanwezigheid van een financier geeft mogelijk op twee manieren een krachtig signaal af aan de wederpartij. Ten eerste geeft de aanwezigheid van de financier een signaal af over de sterkte van de zaak, omdat financiers alleen kansrijke zaken financieren en daar een gedegen onderzoek naar uitvoeren. Dit signaal neemt aan kracht toe als de financier een sterke reputatie in de markt heeft. Ten tweede weet de wederpartij dat de gefinancierde door de aanwezigheid van een procesfinancier minder kwetsbaar is voor kostenverhogende strategieën. De versterking van de onderhandelingspositie betekent dat minder vermogende partijen minder gemakkelijk tot ongunstige schikkingen kunnen worden bewogen door de dreiging van hoge kosten en slepende procedures. ${ }^{9}$

9 T. Cain, 'Third party funding of personal injury tort claims: Keep the baby and change the bathwater', Chicago-Kent Law Review (89) 2014, p. 11-51. 


\subsection{Preventief effect}

Een aantal auteurs ${ }^{10}$ wijst op het preventief effect dat de enkele aanwezigheid en bekendheid van TPLF kan hebben op het gedrag van potentieel verwerende partijen. Dit effect treedt zelfs in zonder dat de verweerder direct met een door een procesfinancier gesteunde wederpartij geconfronteerd wordt. Het gat tussen recht hebben en recht halen kan bij onvermogende partijen relatief groot zijn. Door procesfinanciering worden meer (kansrijke) zaken aangebracht. Hiermee wordt een sterker signaal uitgezonden naar gedaagden in deze en vergelijkbare zaken, dat zij de financiële consequenties van hun daden zullen moeten dragen. Dat signaal kan een anterieure gedragswijziging van (andere) potentiële schadeveroorzakers en wanprestanten teweegbrengen, zodat schadetoebrenging en wanprestatie achterwege blijven.

\subsection{Repeat players}

Ondernemingen die met regelmaat aangesproken worden in vergelijkbare zaken, zijn repeat players. Zij kunnen putten uit ervaring en hebben meestal ook een uitgebreide kring van experts tot hun beschikking. Het geldelijk belang van een zaak overstijgt voor de repeat player al snel de individuele zaak; omdat de uitkomst ook van belang is in andere zaken, zal relatief veel geïnvesteerd worden in de betreffende zaak. De one-shot player heeft daarentegen geen ervaring en geen uitgebreid netwerk van experts. Bovendien is hij financieel kwetsbaarder en reikt zijn belang niet verder dan de onderhavige zaak. Dit betekent niet alleen dat hij niet kan speculeren en de risico's niet kan spreiden over verschillende zaken, zoals de repeat player dat wel kan en doet, maar ook dat hij zich over het algemeen meer risicomijdend zal gedragen. Zodoende wordt het schikkingspotentieel voor de repeat player vergroot. Dit alles zet de one-shot player op achterstand. Wordt een one-shot player bijgestaan door een ervaren procesfinancier die de zaak heeft geselecteerd op haalbaarheid, dan neemt de one-shot player meer de hoedanigheid van een repeat player aan. Daarmee is overigens niet gezegd dat TPLF tot meer of langdurigere procedures leidt. De gelijkmaking van het niveau van kennis en kunde en de financiële middelen zou partijen adequaat kunnen stimuleren om vaker en eerder een schikking of alternatieve geschilbeslechting te beproeven. Immers, het is nu niet meer zo gemakkelijk om minder vermogende eisers af te schrikken, hetzij voorafgaande aan, hetzij tijdens een gerechtelijke procedure. Zodoende zou het voor beide partijen lonend kunnen zijn kosten te besparen door voor een ander procesverloop te kiezen. ${ }^{11}$

\section{De nadelen of risico's van TPLF}

Naast voordelen en kansen komt TPLF ook met nadelen, risico's of aandachtspunten. Deze zal ik in het onderstaande behandelen.

10 De Morpurgo 2011, p. 382-383 en O. Cojo Manuel, 'Third-party litigation funding: Current state of affairs and prospects for its further development in Spain', European Review of Private Law 2014, p. 463.

11 W.H. van Boom \& J.L. Luiten, 'Procesfinanciering door derden', RMThemis 2015, afl. 5, p. 194. 


\subsection{Claimcultuur}

De Nederlandse rechtsorde heeft als uitgangspunt dat eenieder in beginsel zijn eigen schade draagt. Bij een claimcultuur wordt dit uitgangspunt verlaten en ingeruild voor het idee dat bijna altijd wel een verantwoordelijke aan te wijzen is die kan worden aangesproken. Procesfinanciers zouden aan het ontstaan van een claimcultuur bijdragen door de financiële barrières voor procederen te verlagen en actief op zoek te gaan naar winstgevende claims. Dit zou kunnen resulteren in een toename van het aantal rechterlijke procedures, wat tevens leidt tot een toegenomen belasting van de rechterlijke macht. Dit zou vervolgens kunnen leiden tot een verdere uitsluiting van aansprakelijkheid door bedrijven en hogere kosten voor beroeps- en aansprakelijkheidsverzekeringen. ${ }^{12}$ Het tegendeel is echter werkelijkheid. Juist de commerciële insteek van procesfinanciers voorkomt een claimcultuur. Immers, kansarme en kleine zaken zijn voor TPLF meestal niet interessant. Daarnaast geldt dat als het aantal legitieme, kansrijke rechtszaken in Nederland zou toenemen, dat niet per se een slechte ontwikkeling is. Voorlopig is er geen aanleiding om aan te nemen dat TPLF in Nederland zou leiden tot een (verdere) claimcultuur, voor zover daar al geen sprake van is. ${ }^{13}$

\subsection{Informatieasymmetrie}

Procesfinancieringsovereenkomsten met onvoldoende vermogende partijen kunnen grote financiële consequenties voor hen hebben. Voor de leek zullen deze consequenties niet altijd eenvoudig te overzien zijn. Concreet zal met name van belang zijn dat de gefinancierde goed inzicht is verschaft in de verdeling van bevoegdheden gedurende de procedure en in de wijze waarop de mogelijke opbrengst wordt verdeeld. ${ }^{14}$ Het ligt voor de hand om eisen te stellen aan de informatievoorziening door de financier. Dit zal ik behandelen in paragraaf 5 en 6 .

\subsection{Disproportionele beloningen}

Procesfinancieringsovereenkomsten worden gesloten op een markt waar vraag en aanbod elkaar ontmoeten. Zoals bij alle markten ligt altijd het risico van marktfalen op de loer. Een gevaar van TPLF is dat de bedongen percentages van de opbrengst te hoog liggen. Het risico op disproportionele beloningen is het hoogst in situaties waarin de ongelijkheid van partijen het grootst is. Onder de grote aanbieders liggen de bedongen percentages tussen de 20 en $40 \%$. Welk percentage

12 R. Mulheron \& P. Cashman, 'Third-party funding of litigation: A changing landscape', Civil Justice Quarterly 2008, p. 317.

13 Zie voor een duidelijke afrekening met de begrippen 'frivolous litigation' of 'blackmail settlements' I.N. Tzankova, 'Wetsvoorstel collectieve schadevergoedingsactie: een oplossing voor welk probleem ook alweer?', TVP 2017, afl. 4, p. 108-109.

14 Zie Hof Amsterdam 13 december 2011, ECLI:NL:GHAMS:2011:BU8763 (X/Nederlandse Letselstichting). Hierin stond een procesfinancieringsovereenkomst centraal waarin was bepaald dat als de consument niet akkoord wilde gaan met een schikkingsvoorstel dat de financier wel acceptabel vond, zij haar gecedeerde vordering van de financier moest terugkopen, met daarbij voldoening van de tot dan toe gemaakte kosten. Dit betekent de facto dat de consument in kwestie de schikkingsbevoegdheid in haar zaak volledig kwijt was. 
een redelijke beloning vormt voor de procesfinancier is lastig objectief te bepalen, maar verschilt ook sterk qua zaak. ${ }^{15}$ Een hoge beloning is niet per definitie een woekerbeloning. Voor de beantwoording van de vraag of een bepaald percentage een woekerbeloning is, is relevant welke ex ante geschatte kosten de zaak met zich brengt, wat de winkans is en welke diensten de financier levert. ${ }^{16}$ In een ontwikkelde, transparante markt zullen woekerbeloningen vanzelf door de markt worden uitgedreven. Met Van Boom en Luiten ${ }^{17}$ ben ik van mening dat in Nederland, zeker voor consumenten, nog geen sprake is van een volwassen markt voor procesfinanciering. In dergelijke gevallen kunnen eisers zich als het ware genoodzaakt voelen om in te stemmen met beloningspercentages die hoger zijn dan in een markt met veel aanbieders van procesfinanciering. ${ }^{18}$ In het wetsvoorstel collectieve schadevergoedingsactie, dat thans aanhangig is in de Tweede Kamer, komt de rechter bij toekomstige collectieve schadevergoedingsacties een rol toe bij de beoordeling of de procesfinancier een buitensporige (kosten)vergoeding is overeengekomen. Eveneens toetst de rechter de transparantie hierover. ${ }^{19}$ Ook het Gerechtshof Amsterdam in de (WCAM) Fortis-zaak veroorlooft het zich om inzicht te vragen in de kostenstructuur van de diverse claimvehikels, alvorens hij eventueel tot verbindendverklaring van de bereikte schikking inzake de vergoeding voor aandeelhouders over zal gaan. ${ }^{20}$ Mogelijk disproportionele beloningen zijn deels te ondervangen door verschillende procesfinanciers een offerte te laten uitbrengen. Een weldenkende consument die een advocaat op uurbasis zoekt, zal zich alvorens een advocaat aan te stellen een beeld willen vormen van gebruikelijke tarieven. Een partij die financiering zoekt voor een rechtszaak heeft ook de verantwoordelijkheid om zich een beeld te vormen van gebruikelijke TPLF-tarieven, zodat zij niet in zee gaat met een procesfinancier die disproportionele percentages hanteert. Extreem disproportionele percentages kunnen worden vernietigd op grond van misbruik van omstandigheden of dwaling, maar juist hoge verdiensten zorgen voor meer toetreders en een betere marktwerking.

Ik ben van mening dat een maximumtarief voor TPLF onwenselijk is. Ten eerste is het ondoenlijk om een redelijk maximum vast te stellen. Elke zaak is anders, kent andere risico's en kosten, en heeft dus een ander passend tarief. Ten tweede geldt dat hoe lager het percentage dat een financier mag bedingen, des te strenger de eisen die hij zal moeten stellen, waardoor minder zaken voor financiering in aanmerking komen. Ten derde lijkt mij dat professionele partijen en consumenten met een grote claim ook zonder maximumafdrachtpercentage in staat zouden moeten zijn om een adequaat tarief overeen te komen door meerdere offertes op

15 De auteur heeft gehoord van een procesfinancieringsovereenkomst betreffende een vordering tegen de Noord-Koreaanse staat, waarbij tussen twee professionele partijen een percentage van $90 \%$ is overeengekomen.

16 Wat dit laatste betreft: de financier kan optreden als sec financier, maar kan ook de gefinancierde toegang bieden tot zijn netwerk van advocaten en experts.

17 Van Boom \& Luiten 2015, p. 195.

18 Mulheron \& Cashman 2008, p. 317; Cain 2014, p. 13; Kamerstukken II 2011/12, 33126, 6, p. 6.

19 Kamerstukken II 2018/19, 34608, 6, p. 25: 'Daarnaast kan de rechter toetsen of de derdenfinancier geen buitensporige en ontransparante kosten in rekening brengt voor de financiering.' 
te vragen en te onderhandelen. Consumenten met een claim tot enkele tienduizenden euro's kunnen mogelijk niet bij de grotere financiers terecht, die een reputatie te beschermen hebben, redelijk transparant zijn en hun cliënten goed informeren. Deze groep consumenten is dus aangewezen op een ondoorzichtiger deel van de markt, waar disproportionele beloningen een reëler gevaar vormen. Deze consumenten kunnen allereerst zichzelf beschermen door verschillende offertes op te vragen en kunnen achteraf extreem disproportionele percentages laten vernietigen op grond van dwaling of misbruik van omstandigheden. Additionele bescherming voor consumenten in de vorm van bijvoorbeeld een geschillenregeling lijkt mij overigens wel wenselijk. In paragraaf 5 en 6 zal ik dit verder uitwerken.

\subsection{Gebrek aan kwaliteit en liquiditeit}

De eiser wendt zich tot een procesfinancier om het financiële risico tegen een percentage op hem over te hevelen. De eiser doet dit omdat hij ervan uitgaat dat de procesfinancier meer liquide is dan hij dat zelf is. Momenteel heeft de gefinancierde echter geen enkele garantie met betrekking tot de liquiditeit van de procesfinancier. Zo is de situatie mogelijk dat een eiser zich wendt tot een procesfinancier die eveneens onvoldoende kapitaalkrachtig blijkt te zijn. Een te kleine kapitaalbuffer bij de procesfinancier kan voor hem aanleiding zijn om snel (en te goedkoop) te schikken. Daarnaast zou de procesfinancier failliet kunnen gaan, waarna de eiser op zoek zou moeten naar een nieuwe geldschieter. Afhankelijk van de procesfinancieringsovereenkomst zou de claimant gehouden zijn om de tot het faillissement gemaakte kosten te voldoen.

Als de procesfinancier naast financiering ook bijvoorbeeld een actieve rol neemt in het (mede)bepalen van de strategie of het kiezen van een gemachtigde, kunnen gebrekkige ervaring, kennis en kwaliteit de belangen van gefinancierde verder schaden. Het gebrek aan liquiditeit en kwaliteit is voor een groot deel te ondervangen door kwaliteitseisen te stellen aan de liquiditeit, solvabiliteit, governance en transparantie van procesfinanciers. Dit zou in de vorm van een dwingend vergunningstelsel, zelfregulering ${ }^{21}$ of een wettelijke regeling kunnen.

\subsection{Belangentegenstellingen bij advocaat}

Procesfinanciers zien graag een bepaalde vorm van financiële alignment bij de ingehuurde advocaat. ${ }^{22}$ Zo wordt vaak een laag-hoog tarief bedongen, waarbij de advocaat in eerste instantie een kostendekkend tarief in rekening brengt, maar bij een succesvol verloop dezelfde uren tegen een afgesproken hoger tarief in rekening brengt. Dit beperkt het kapitaalbeslag en het risico voor de procesfinancier. Zelfs al zou een advocaat worden betaald op basis van een vast uurtarief, kan hij financieel afhankelijk zijn van de procesfinancier. Dit is bijvoorbeeld het geval als

21 Bij de behandeling van het Voorontwerp wetsvoorstel afwikkeling massaschade in collectieve actie suggereerde de minister van Justitie dat procesfinanciers die aan dergelijke eisen voldoen, kunnen worden voorzien van een keurmerk of worden opgenomen in een register. Kamerstukken II 2011/12, 33126, 6, p. 9.

22 Tuil \& Visscher 2010, p. 15. 
de cliënt niet vermogend genoeg is om eventueel verhaal te bieden als de financier zich terugtrekt. Daarnaast is de advocaat ook een repeat player en zal een lucratief samenwerkingsverband met de procesfinancier niet graag kwijtraken. De advocaat ziet zich geconfronteerd met twee partijen, waardoor de verleiding aanwezig is om de wensen van de financier in acht te nemen, te laten prevaleren, of de cliënt te bewegen ook de zienswijze van de financier over te nemen.

Het vormen van banden tussen financiers en advocaten kan ook op informele wijze plaatsvinden en is daarom lastig te voorkomen. Een rigoureuze maatregel zou zijn om het procesfinanciers te verbieden zich met de advocaatkeuze te bemoeien. Een alternatief is om de keuze van de advocaat aan de goedkeuring van de financier te onderwerpen of een kostenmaximum overeen te komen. De vraag is ook of de belangentegenstelling bij TPLF groter is dan in de traditionele rechtsverhouding tussen een advocaat en een grote belangrijke cliënt, of in de situatie waarbij een derde zich borg heeft gesteld voor de advocaatkosten. ${ }^{23}$ In de laatste situaties is een advocaat immers voor wat betreft omzet en verhaal ook afhankelijk van zijn cliënt of een derde. Beperkingen voor de financier om zich te bemoeien met de advocaatkeuze hebben ook een nadeel: een financier is als repeat player beter in staat de beste advocaat voor de desbetreffende zaak te selecteren en gunstigere tarieven overeen te komen met deze advocaat, waarvan de kostenvoordelen ook deels de gefinancierde ten goede komen.

De meningen over de vraag of het een advocaat toegestaan moet zijn om zowel de claimant als de procesfinancier bij te staan (de laatste met advies over de kans van de vordering en processtrategie), zijn verdeeld. Van Boom ${ }^{24}$ is van mening dat er eenvoudig een belangenconflict kan ontstaan, daar processtrategie en schikkingsbereidheid van claimant en financier kunnen divergeren. Van Boom acht het onwenselijk en onverstandig om zowel de claimant als de procesfinancier bij te staan, omdat zodra een conflict zich verwezenlijkt, de advocaat zich moet terugtrekken. ${ }^{25}$ Samen met Luiten ${ }^{26}$ sta ik hier genuanceerder in en ben van mening dat deze situatie vergeleken kan worden met een joint venture. Bij een joint venture is het niet ongebruikelijk dat de samenwerkende commerciële partijen zich door dezelfde advocaat laten vertegenwoordigen. De belangen van de partijen stemmen in beginsel overeen, maar er bestaat altijd een kans op een belangenconflict. De advocaat is dan gehouden zich voor beide partijen volledig terug te trekken. Dit brengt grote risico's met zich mee voor de gefinancierde die zich bij terugtrekking van de advocaat geconfronteerd ziet met zowel een conflict met de financier als een verlies van zijn gemachtigde ten aanzien van de gefinancierde 
vordering. Op zijn minst consumenten zouden van dit risico op de hoogte moeten worden gesteld.

\subsection{Geheimhoudingsplicht advocaat}

Om een goede inschatting te kunnen maken van de omvang, risico's en winkansen van een zaak zal een procesfinancier zo veel mogelijk informatie willen. Hij zal daarbij ook toegang willen tot informatie die normaliter zou vallen onder de geheimhoudingsplicht van een advocaat. De gedragsregels maken het mogelijk deze informatie te delen met instemming van de cliënt. De cliënt heeft hierin ook weinig keus: zonder het delen van informatie zal een procesfinancier immers geen goede inschatting van de zaak kunnen maken en weigeren om de zaak te financieren. Het is denkbaar dat een advocaat informatie deelt met een (potentiële) procesfinancier zonder uitdrukkelijke instemming van de cliënt, omdat hij afhankelijk is van de procesfinancier voor zijn bezoldiging, zeker als hij al werkzaamheden heeft verricht en de cliënt onvoldoende verhaal biedt. Dit is allemaal niet problematisch als de procesfinancier vervolgens besluit de zaak te financieren. Echter, de procesfinancier zou ook kunnen besluiten de zaak niet te financieren. De procesfinancier is dan, behoudens een daartoe strekkende afspraak, niet gehouden aan geheimhouding. Voorts heeft een procesfinancier geen verschoningsrecht en is dus een potentieel doelwit voor een exhibitieactie op grond van art. 834a Rv.

Er is een balans nodig qua informatievoorziening: enerzijds heeft de financier voldoende informatie nodig om een adequate inschatting te kunnen maken, anderzijds moeten de belangen van de cliënt zo goed mogelijk worden gewaarborgd. Sowieso verdient het aanbeveling om de procesfinancier te onderwerpen aan een geheimhoudingsplicht ten aanzien van alle ontvangen informatie, onafhankelijk van zijn beslissing om al dan niet te financieren.

\section{Reguleringsmogelijkheden}

In de beschrijving van de kansen en risico's van TPLF is hier en daar al gewezen op mogelijke oplossingsrichtingen waarmee deze risico's kunnen worden ingedamd. Het is interessant om qua reguleringsmogelijkheden naar Engeland te kijken als zijnde de meest ontwikkelde markt voor TPLF. Procesfinanciers in Engeland hebben een gedragscode vastgesteld, die regels stelt ten aanzien van (i) de financiële gezondheid van de financier; (ii) het volledig informeren van de claimant; (iii) de omstandigheden waaronder een overeenkomst mag worden beëindigd; en (iv) de bevoegdhedenverdeling tussen financier, claimant en advocaat. ${ }^{27}$ Ten aanzien van de financiële gezondheid bepaalt art. 9.4 van de gedragscode dat procesfinanciers over voldoende kapitaal moeten beschikken ter dekking van de risico's van lopende procedures voor ten minste 36 maanden. Tevens dient de procesfinancier met regelmaat verantwoording over de liquiditeit, solvabiliteit en

27 Code of Conduct for Litigation Funders, gepubliceerd in november 2011 en laatst gewijzigd in november 2016. Zie associationoflitigationfunders.com/documents/. 
cashflow af te leggen tegenover de Association of Litigation Funders en haar te informeren zodra hierin een significante wijziging optreedt.

Onder art. 11 wordt beëindiging van de procesfinancieringsovereenkomst toegestaan als er sprake is van een limitatief aantal omstandigheden. Beëindiging is onder andere mogelijk wanneer de gefinancierde de voorwaarde van de overeenkomst schendt. Andere beëindigingsgronden zijn overigens redelijk ruim geformuleerd. Zo is het voor de financier ook mogelijk de procesfinancieringsovereenkomst te beëindigen indien hij 'reasonably believes that the dispute is no longer commercially viable'.

Ten aanzien van de informatieverstrekking bepaalt de gedragscode dat de procesfinancieringsovereenkomst uitsluitsel moet geven over de manier waarop zal worden omgegaan met een eventuele kostenveroordeling en de verdeling van de bevoegdheden tussen financier, gefinancierde en advocaat. Daarnaast dient de financier het mogelijk te maken en te stimuleren dat de gefinancierde onafhankelijk advies inwint over de consequenties van het aangaan van de procesfinancieringsovereenkomst. De gedragscode verbiedt de procesfinancier te pogen de advocaat te beïnvloeden of hem te bewegen controle over te dragen aan de financier (art. 9.2 en 9.3). Voorts moeten procesfinanciers een klachtenprocedure met adequate waarborgen hebben en een dispuutresolutiemechanisme (art. 13.2 en 15).

Er is geen onderzoek gedaan naar de compliance van Britse procesfinanciers met de gedragscode. Aangezien de belangrijkste procesfinanciers onderdeel waren van de werkgroep die de gedragscode heeft opgesteld, mag worden verondersteld dat de compliance onder de leden van de Association of Litigation Funders hoog is. ${ }^{28}$

\section{Aanbevelingen}

Nederland kent noch een vereniging van procesfinanciers, noch een gedragscode. Het lijkt mij dat hier behoefte aan is, en dat een dergelijke vereniging van grote meerwaarde kan zijn voor de bredere bekendheid en acceptatie van TPLF, het voorkomen van misstanden bij procesfinanciers door in te zetten op compliance met een gedragscode, en het behartigen van de belangen van procesfinanciers bij wet- en regelgevende instellingen. Een gedragscode zou mijns inziens minimaal de volgende elementen moeten bevatten:

- Informatieverstrekking: een gedragscode zou minimumeisen moeten stellen aan de inhoud en wijze waarop precontractuele informatie over de kansen en risico's van de procesfinancieringsovereenkomst aan de claimant wordt verstrekt.

- Geschillenregeling: ik acht het aanbevelenswaardig om op voorhand duidelijkheid te verschaffen over enkele procesregels aangaande het oplossen van

28 De sancties bij non-compliance zijn beperkt. De Association of Litigation Funders kan haar leden een boete opleggen van $£ 500$ of het lidmaatschap schorsen dan wel opheffen. Hoewel dit reputatieschade oplevert, kan het een procesfinancier er niet van weerhouden zijn praktijk voort te zetten. Lidmaatschap van de Association of Litigation Funders is immers geen voorwaarde om procesfinanciering te verstrekken. 
een mogelijk geschil tussen financier en gefinancierde. Zo zou een geschil kunnen worden voorgelegd aan een onafhankelijke derde die betaald wordt door de financier. Deze derde zou bijvoorbeeld het Klachteninstituut Financiele Dienstverlening of een arbiter uit een lijst van beschikbare arbiters kunnen zijn. De derde beoordeelt het geschil op basis van de vastgelegde contractuele afspraken, compliance met een Nederlandse gedragscode voor procesfinanciers en redelijkheid en billijkheid.

- Financiële gezondheid: het introduceren van waarborgen dat de procesfinancier een financieel gezonde huishouding heeft, zodat de procedure van de claimant niet opeens stilvalt door het wegvallen van financiering, en dat schikkingsgelden bijvoorbeeld op derdenrekeningen terechtkomen.

- Controle: het voorkomen dat de controle over de claim en de bevoegdheid tot schikking zozeer bij de financier komt te liggen, dat de cliënt feitelijk niets kan ondernemen tegen een onredelijke schikking die de financier uit de kosten helpt, maar de cliënt ten onrechte te weinig biedt.

\section{Conclusie}

Een deel van de bezwaren tegen procesfinanciering is ongefundeerd, of overdreven. Omdat procesfinanciers hoge eisen stellen aan de (ver)haalbaarheid, omvang en beperking van risico's is het onwaarschijnlijk dat TPLF zal leiden tot een claimcultuur. TPLF zorgt wel voor een driepartijenverhouding, die mogelijk voor complicaties kan zorgen. Ook kan TPLF grote consequenties voor de gefinancierde hebben, zeker in een volledig ongereguleerde markt als de Nederlandse. Grotere partijen moeten over het algemeen worden geacht deze consequenties te kunnen overzien en daarop te kunnen anticiperen. Consumenten en kleinere partijen zouden echter meer bescherming behoeven. Een gedragscode kan hierbij behulpzaam zijn en misstanden op voorhand proberen te voorkomen. Als deze handschoen door procesfinanciers in Nederland wordt opgepakt, kan TPLF een nuttige bijdrage leveren aan de borging van de toegang tot het recht. 